\begin{tabular}{ccc}
\hline International Journal of Engineering \& Technology, 7 (4.30) (2018) 75-79 \\
SPC \\
Website: www.sciencepubco.com/index.php/IJET \\
Research paper
\end{tabular}

\title{
Comparative Study on Structural, Electrical Transport and Magnetic Properties of Cr-Doped in Charge-Ordered $\operatorname{Pr}_{0.75} \mathrm{Na}_{0.25} \mathrm{Mn}_{1-X} \mathrm{Cr}_{x} \mathrm{O}_{3}$ and $\mathrm{Nd}_{0.75} \mathrm{Na}_{0.25} \mathrm{Mn}_{1-Y} \mathrm{Cr}_{y} \mathbf{0}_{3}$ Manganites
}

\author{
Rabiatul Adawiyah Zawawi ${ }^{1}$, Nurul Nasuha Khairulzaman ${ }^{2}$, Suhadir Shamsuddin ${ }^{3 *}$, Norazila Ibrahim ${ }^{4}$ \\ ${ }^{1,2,3}$ Ceramics and Amorphous Group, Faculty of Applied Sciences and Technology, Pagoh Higher Education Hub, \\ Universiti Tun Hussein Onn Malaysia, Pagoh Campus, 84600 Pagoh, Johor, Malaysia. \\ ${ }^{4}$ Faculty of Applied Sciences, Universiti Teknologi MARA, 40450 Shah Alam, Selangor, Malaysia. \\ *Corresponding author E-mail:suhadir@uthm.edu.my
}

\begin{abstract}
Cr doping in charge-ordered $\operatorname{Pr} 0.75 \mathrm{Na} 0.25 \mathrm{Mn}_{1-x} \mathrm{Cr}_{x} \mathrm{O}_{3}$ and $\mathrm{Nd}{ }_{0.75} \mathrm{Na} 0.25 \mathrm{Mn}_{1-y} \mathrm{Cr}_{y} \mathrm{O}_{3}$ have been synthesized using conventional solid-state method to investigate its effect on structural, electrical transport and magnetic properties. X-ray diffraction (XRD) analysis for both compounds showed that the samples were crystallized in an orthorhombic structure with Pnma group. The unit cell volume value decrease as the Cr-doped increased indicating the possibility of $\mathrm{Mn}^{3+}$ ion was replaced by $\mathrm{Cr}^{3+}$ due to the different of ionic radius. The temperature dependence of electrical resistivity showed an insulating behavior down to the lower temperature the both parent compound $\left(x=0\right.$ and $y=0$ ). Successive substitution of $\mathrm{Cr}$ at $\mathrm{Mn}$-site in $\operatorname{Pr}_{0.75} \mathrm{Na}_{0.25} \mathrm{Mn}_{1-x} \mathrm{Cr}_{x} \mathrm{O}_{3}$ manganites induced the metal-insulator (MI) transition temperature around $T_{M I} \sim 120 \mathrm{~K}$ and $T_{M I} \sim 122 \mathrm{~K}$ for $x=0.02$ and $x=0.04$ samples respectively suggestively due to the enhancement of double-exchange (DE) mechanism as a result of suppress the CO state. Analysis of resistivity data of $d \ln \rho / d T^{-1} \mathrm{vs}$. $T$ in $\mathrm{Nd}_{0.75} \mathrm{Na}_{0.25} \mathrm{Mn}_{1-y} \mathrm{Cr}_{y} \mathrm{O}_{3}$ manganite, showed a peak around $210 \mathrm{~K}$ and $160 \mathrm{~K}$ for $y=0$ and 0.02 samples respectively while no peak was observed for $y=0.05$ sample indicate the charge-ordered (CO) weakened. AC susceptibility, $\chi$ ' measurements in $\operatorname{Pr}_{0.75} \mathrm{Na}_{0.25} \mathrm{Mn}_{1-x} \mathrm{Cr}_{x} \mathrm{O}_{3}$ exhibits paramagnetic to ferromagnetic-like with curie temperature, $T_{C}$ increases from $132 \mathrm{~K}$ for $x=0.02$ to $141 \mathrm{~K}$ for $x=0.04 \mathrm{with} \mathrm{Cr}$ content indicate the suppression of $\mathrm{CO}$ state meanwhile in $\mathrm{Nd}_{0.75} \mathrm{Na}_{0.25} \mathrm{Mn}_{1-y} \mathrm{Cr}_{y} \mathrm{O}_{3}$ showed paramagnetic to anti-ferromagnetic transition as Neel temperature $T_{N}$ increases from $115 \mathrm{~K}$ for $y=0.02$ to $125 \mathrm{~K}$ for $y=0.05$.
\end{abstract}

Keywords: Charge-Ordered; Cr-Doped; Double-Exchange Mechanism; Electrical Transport; Magnetic Properties.

\section{Introduction}

The discovery of colossal magnetoresistance (CMR) effect in rareearth perovskite-type manganites with general composition of type $\mathrm{Re}_{1-\mathrm{x}} \mathrm{A}_{\mathrm{x}} \mathrm{MnO}_{3}(\mathrm{Re}=\mathrm{a}$ trivalent rare-earth ion, $\mathrm{A}=\mathrm{a}$ divalent alkaline-earth) have attracted much attention in these recent years [1-7]. In addition, studies on these rare-earth manganites have revealed that CMR effect which is commonly attributed to the double- exchange (DE) mechanism is also suggested to be related to the Jahn-Teller (JT) effect and charge ordering (CO) [8] and the lattice distortion [9].

In particular, the $\operatorname{Pr}_{0.75} \mathrm{Na}_{0.25} \mathrm{MnO}_{3}$ and $\mathrm{Nd}_{0.75} \mathrm{Na}_{0.25} \mathrm{MnO}_{3}$ compound has attracted due to the existence of $\mathrm{CO}$ transition at relatively high temperature, $T_{C O} \sim 220 \mathrm{~K}$ for $\operatorname{Pr} 0.75 \mathrm{Na}_{0.25} \mathrm{MnO}_{3}$ and $T_{C O} \sim 170 \mathrm{~K}$ for $\mathrm{Nd}_{0.75} \mathrm{Na}_{0.25} \mathrm{MnO}_{3}$ compared to antiferromagnetic (AFM) interaction [10-12]. The presence of CO state was suggested to be related to the presence of an equal ratio of $\mathrm{Mn}^{3+}$ and $\mathrm{Mn}^{4+}$ where the ions align themselves in an ordered pattern [1315].

$\mathrm{Mn}$ site substitutions of $\mathrm{Cr}$ on perovskite manganites have attracted great interest as the $\mathrm{Cr}^{3+}$ ion is iso-electronic with the $\mathrm{Mn}^{4+}$ ion [16-20]. It is reported that among the different studied doping elements, $\mathrm{Cr}$ is the most efficient one to induce a metal insulator transition in the $\mathrm{CO}$ undoped insulators and leads to a much higher CMR effect [16]. For example, in $\mathrm{Nd}_{0.7} \mathrm{Sr}_{0.3} \mathrm{Mn}_{1-x} \mathrm{Cr}_{x} \mathrm{O}_{3}$ and $\mathrm{La} 0.7 \mathrm{Ca} 0.3 \mathrm{Mn}_{1-x} \mathrm{Cr}_{x} \mathrm{O}_{3}$ the electrical transport behaviour shows that the metal-insulator (MI) transition shift to lower temperature and weakened gradually as the $\mathrm{Cr}$ content increased due to DE mechanism between $\mathrm{Mn}^{3+}-\mathrm{O}-\mathrm{Mn}^{4+}$ [17].

Meanwhile all samples for $\mathrm{Cr}$ doped up to 0.3 in compound $\mathrm{La} 0.67 \mathrm{Ca} 0.33 \mathrm{Mn}_{1-x} \mathrm{Cr}_{x} \mathrm{O}_{3}$ exhibit a ferromagnetic-paramagnetic (FM$\mathrm{PM})$ transition with $T_{C}$ decreased rather slowly with increasing $\mathrm{Cr}$ content for $x \leq 0.2$ [18]. When doping on $\mathrm{Mn}$ sites with $\mathrm{Cr}^{3+}$ ions, the transport and magnetic properties of the manganites will show some interesting behaviors. Thus, considering all the above, the studies on the effects of $\mathrm{Cr}$ doping on $\mathrm{Mn}$ site is expected to understand the physical nature of doping effect in manganites. However, to the best of our knowledge, there are only few studies on $\mathrm{Nd}_{0.75} \mathrm{Na} 0.25 \mathrm{MnO}_{3}$ and the effect of $\mathrm{Cr}$ doped in monovalent manganite of $\operatorname{Pr}_{0.75} \mathrm{Na}_{0.25} \mathrm{MnO}_{3}$ have not been reported yet on structural, transport and magnetic properties.

In this work, we report the effect of magnetic ion, $\mathrm{Cr}$ doping at the $\mathrm{Mn}$ site on the structural, electrical transport and magnetic properties of $\operatorname{Pr}_{0.75} \mathrm{Na}_{0.25} \mathrm{MnO}_{3}$ and $\mathrm{Nd}_{0.75} \mathrm{Na}_{0.25} \mathrm{MnO}_{3}$ manganite. The $\mathrm{Cr}^{3+}$ ion was suggested to be very effective element to suppress $\mathrm{CO}$ as well as induced the phase transition. 
Table 1. MI transition temperature $\left(T_{\mathrm{MI}}\right)$, Curie temperature $\left(T_{\mathrm{C}}\right)$, Neel temperature $\left(T_{\mathrm{N}}\right)$, lattice parameters, unit cell volume $(V)$, density $(D)$ and porosity of $\mathrm{Pr}_{0.75} \mathrm{Na}_{0.25} \mathrm{Mn}_{1-x} \mathrm{Cr}_{x} \mathrm{O}_{3}(0 \leq x \leq 0.04)$ and $\mathrm{Nd}_{0.75} \mathrm{Na}_{0.25} \mathrm{Mn}_{1-y} \mathrm{Cr}_{y} \mathrm{O}_{3}(0 \leq y \leq 0.05)$

\begin{tabular}{|c|c|c|c|c|c|c|c|c|c|}
\hline \multirow[t]{2}{*}{ Samples } & \multirow[t]{2}{*}{$\begin{array}{l}T_{M I}(\mathrm{~K}) \\
( \pm 0.1)\end{array}$} & \multirow[t]{2}{*}{$\begin{array}{c}T_{C}(\mathrm{~K}) \\
( \pm 0.1)\end{array}$} & \multirow[t]{2}{*}{$\begin{array}{l}T_{N}(\mathrm{~K}) \\
( \pm 0.1)\end{array}$} & \multicolumn{3}{|c|}{$\begin{array}{l}\text { Lattice parameter } \\
\qquad( \pm 0.001)\end{array}$} & \multirow[t]{2}{*}{$\begin{array}{l}V(\AA)^{3} \\
( \pm 0.1)\end{array}$} & \multirow[t]{2}{*}{$\begin{array}{c}D\left(\mathrm{~g} / \mathrm{cm}^{3}\right) \\
( \pm 0.01)\end{array}$} & \multirow{2}{*}{$\begin{array}{c}\text { Porosity } \\
(\%) \\
( \pm 0.1) \\
\end{array}$} \\
\hline & & & & $a(\AA)$ & $b(\AA)$ & $c(\AA)$ & & & \\
\hline$x=0.0$ & - & - & - & 5.446 & 7.696 & 5.445 & 228.2 & 5.71 & 11.0 \\
\hline$x=0.04$ & 122.0 & 141.0 & - & 5.449 & 7.659 & 5.444 & 227.2 & 5.51 & 14.0 \\
\hline$y=0.0$ & - & - & - & 5.446 & 7.696 & 5.445 & 228.2 & 5.97 & 5.00 \\
\hline$y=0.02$ & - & - & 115.0 & 5.437 & 7.697 & 5.450 & 228.1 & 5.96 & 6.00 \\
\hline$y=0.05$ & - & - & 125.0 & 5.448 & 7.669 & 5.443 & 227.4 & 5.88 & 7.00 \\
\hline
\end{tabular}

\section{Experimental Method}

\subsection{Sample preparation}

The polycrystalline samples of $\operatorname{Pr}_{0.75} \mathrm{Na}_{0.25} \mathrm{Mn}_{1-x} \mathrm{Cr}_{x} \mathrm{O}_{3}(x=0,0.02$ and 0.04$)$ and $\mathrm{Nd}_{0.75} \mathrm{Na}_{0.25} \mathrm{Mn}_{1-y} \mathrm{Cr}_{y} \mathrm{O}_{3}(y=0,0.02$ and 0.05$)$ from the stoichiometric amount of $\mathrm{Pr}_{2} \mathrm{O}_{3}, \mathrm{Na}_{2} \mathrm{CO}_{3}, \mathrm{MnO}_{2}$, and $\mathrm{Cr}_{2} \mathrm{O}_{3}$ powders and $\mathrm{Nd}_{2} \mathrm{O}_{3}, \mathrm{Na}_{2} \mathrm{CO}_{3}, \mathrm{MnO}_{2}$ and $\mathrm{Cr}_{2} \mathrm{O}_{3}$ powders with high purity $(\geq 99.99 \%)$ respectively were prepared using conventional solid-state reaction method. The starting material were mixed and ground thoroughly in an agate mortar with pestle for approximately 2 hours to get homogeneous powders. The homogeneous fine powders were then calcined in air at $1000{ }^{\circ} \mathrm{C}$ for 24 hours at the rate of $15{ }^{\circ} \mathrm{C} / \mathrm{min}$ on heating with several intermediate grinding followed by cooling at rate of $1^{\circ} \mathrm{C} / \mathrm{min}$. The resultant powder was reground for another 2 hours. Such calcined mixtures were then pressed into pellets with $13 \mathrm{~mm}$ diameter and 2-3 mm thickness under 6 tonnes and sintered in air at $1200{ }^{\circ} \mathrm{C}$ for 24 hours in a Protherm Furnace Model PLF130/15 with the heating rate of the order $15{ }^{\circ} \mathrm{C} / \mathrm{min}$ and cooling rate $1{ }^{\circ} \mathrm{C} / \mathrm{min}$ to ensure a better crystallization.

\subsection{Sample characterization}

The structural characterization of all samples were characterized by X-ray diffraction (XRD) using Bruker D8 Advance model with a $\mathrm{CuK}_{\alpha}(1.544 \AA)$ radiation at room temperature. The sample was scanned continuously in the range of $20^{\circ} \leq 2 \theta \leq 80^{\circ}$ with a scanning rate of $2 \% \mathrm{~min}$ and then the structural analyses were carried out by X'Pert HighScore software to confirm the crystalline phase of the samples. Electrical resistivity as a function of temperature was measured by standard four probe method with silver point contact in a Janis model CCS 350T cryostat and controlled by a LakeShore Model 330 under zero magnetic fields in the temperature range $50-300 \mathrm{~K}$. The temperature dependence of AC susceptibility was measured in CryoBIND-T system in conjunction with a 7265 DSP lock-in-amplifier and an oscillator at $240 \mathrm{~Hz}$ in the temperature range of $50-300 \mathrm{~K}$ to determine the Curie temperatures of the samples. Bulk density of the samples was determined by employing the Archimedes principle using acetone as the liquid buoyant.

\section{Result and Discussion.}

\subsection{Structural analysis}

Room temperature powder XRD patterns of $\operatorname{Pr}_{0.75} \mathrm{Na}_{0.25} \mathrm{Mn}_{1-x} \mathrm{Cr}_{x} \mathrm{O}_{3} \quad(x=0,0.02$ and 0.04$)$ samples and $\mathrm{Nd}_{0.75} \mathrm{Na}_{0.25} \mathrm{Mn}_{1-y} \mathrm{Cr}_{y} \mathrm{O}_{3}(y=0,0.02$ and 0.05$)$ as shown in Figure 1 and Figure 2 respectively. The analysis revealed that the structure of the both compound were crystallized in orthorhombic with space group Pnma and all samples were found in a single phase without the presence of any impurity peaks and it is in line with the structure reported from the previous study $[19,20]$ MI transition temperature $\left(T_{M I}\right)$, Curie temperature $\left(T_{C}\right)$, Neel temperature $\left(T_{N}\right)$, lattice parameters, unit cell volume $(V)$, density
(D) and porosity for all samples are tabulated in Table 1 . As the $\mathrm{Cr}$ content increased, a regular shift toward higher $2 \theta$ was observed indicating the decreasing in unit cell volume as reported in previous study by [21]. This is possibly due to the relatively larger of $\mathrm{Mn}^{3+}$ ion with higher ionic radius $(0.645 \AA)$ partially substitute of $\mathrm{Cr}^{3+}$ ions that has a smaller ionic radius $(0.615 \AA)$ as proposed by [22] in $\mathrm{La}_{0.67} \mathrm{Ba}_{0.33} \mathrm{Mn}_{1-x} \mathrm{Cr}_{x} \mathrm{O}_{3}$ compound [22]. Apart from that, the substitution of $\mathrm{Cr}^{3+}$ for all samples were also suggested to induce the lattice distortion and rearrangement of atom as a result of smaller cation in the $\mathrm{B}$-site of the $\mathrm{ABO}_{3}$ perovskite structure is responsible for the reduction in unit cell volume [23-25] and it is also supported by $D$ values when $\mathrm{Cr}$ doped in these manganite compound.

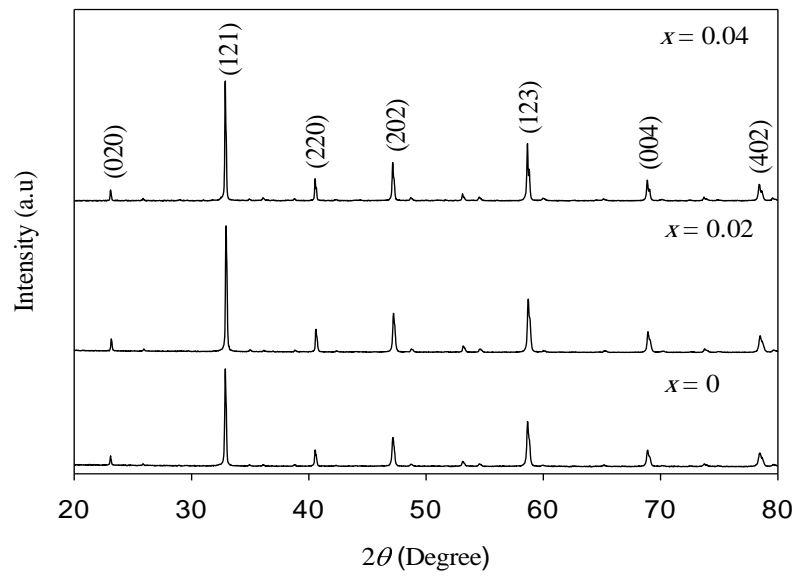

Fig. 1: X-ray powder diffraction (XRD) pattern of $\operatorname{Pr}_{0.75} \mathrm{Na}_{0.25} \mathrm{Mn}_{1-x} \mathrm{Cr}_{x} \mathrm{O}_{3}$ $(0 \leq x \leq 0.04)$ samples

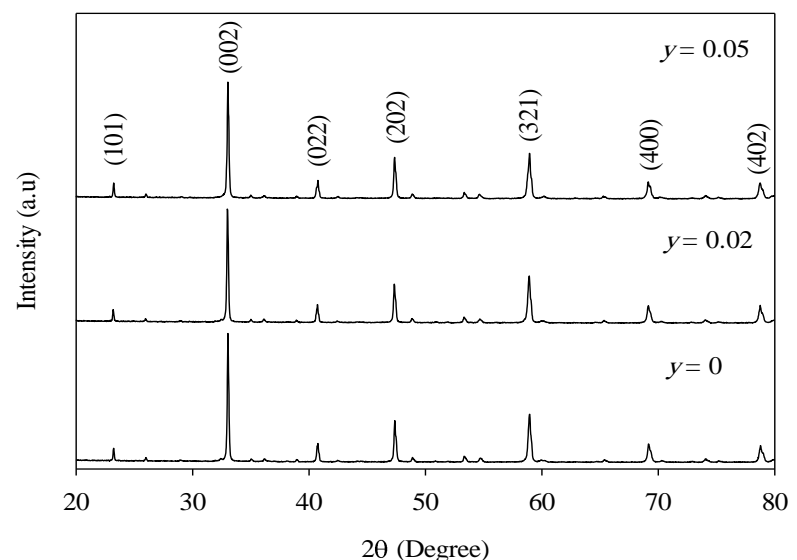

Fig. 2: X-ray powder diffraction (XRD) pattern of $\mathrm{Nd}_{0.75} \mathrm{Na}_{0.25} \mathrm{Mn}_{1-y} \mathrm{Cr}_{y} \mathrm{O}_{3}$ $(0 \leq y \leq 0.05)$ samples

\subsection{Electrical transport properties}

Figure 3 shows the temperature dependence of electrical resistivity in the temperature range $50-300 \mathrm{~K}$ for $\operatorname{Pr}_{0.75} \mathrm{Na}_{0.25} \mathrm{Mn}_{1}$ ${ }_{x} \mathrm{Cr}_{x} \mathrm{O}_{3}(x=0,0.02$ and 0.04$)$ under zero magnetic field. The sample with $x=0$ exhibit an insulating behavior without showing any 
transition of MI consistent with the previous study [26]. A MI transition was observed at $120 \mathrm{~K}$ and $122 \mathrm{~K}$ for $\quad x=0.02$ and $x=0.04$ samples respectively. This behavior is attributed to the fact that the doping of $\mathrm{Cr}^{3+}$ ion disturbs the lattice and also dilutes the double-exchange (DE) by reducing $\mathrm{Mn}^{3+} / \mathrm{Mn}^{4+}$ ratio, which is assumed to produce strong DE compared to that DE between $\mathrm{Mn}^{3+} / \mathrm{Mn}^{4+}$. The shifting of MI transition temperature, $T_{M I}$ from $120 \mathrm{~K}(x=0.02)$ to $122 \mathrm{~K}(x=0.04)$ suggest the enhancement of DE-like mechanism of $\mathrm{Cr}^{3+}-\mathrm{O}-\mathrm{Mn}^{3+}$ as a result of weakening the JT effect causing the CO state to be weakened $[13,27]$

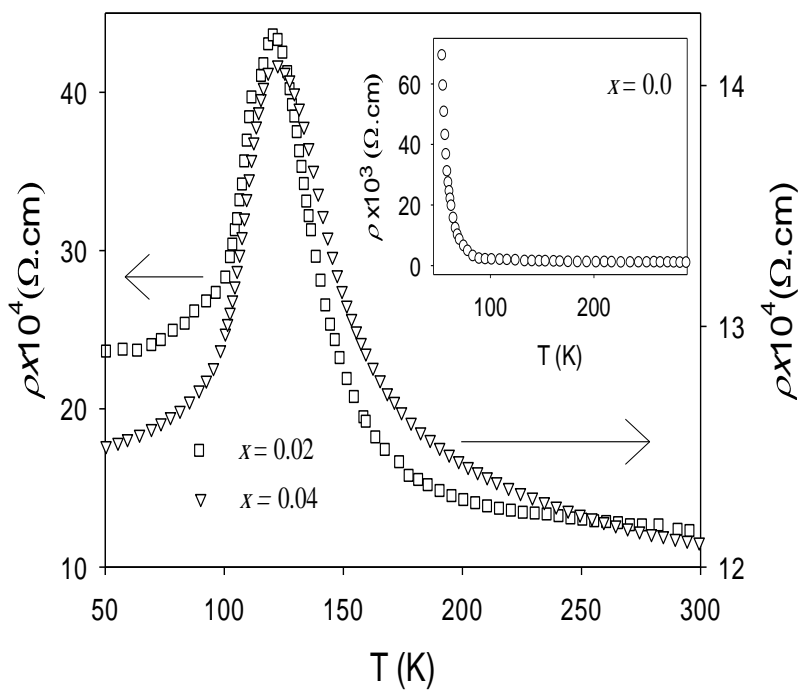

Fig. 3: Temperature dependence of the electrical resistivity of $\mathrm{Pr}_{0.75} \mathrm{Na}_{0.25} \mathrm{Mn}_{1-x} \mathrm{Cr}_{x} \mathrm{O}_{3}(0 \leq x \leq 0.04)$. Inset is $\rho$ versus $T$ for $x=0$ sample.

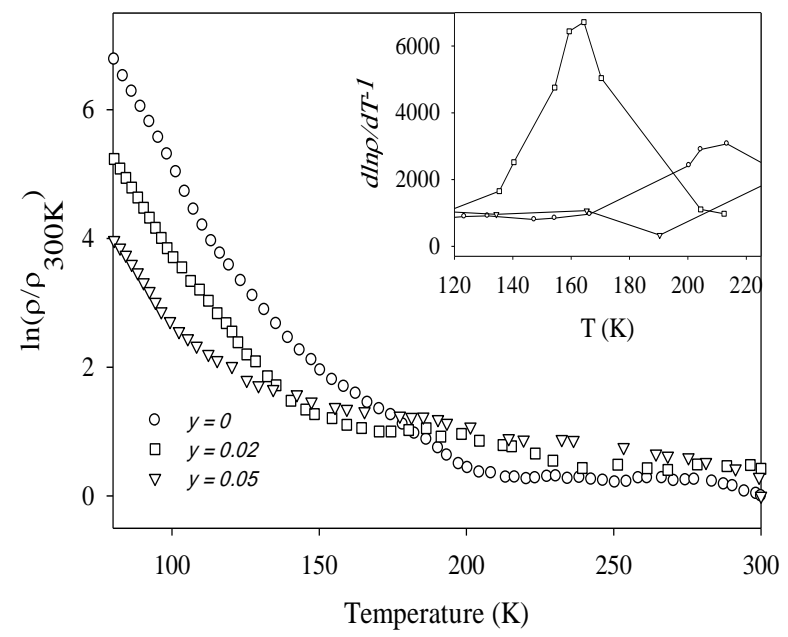

Fig. 4: Temperature dependence of electrical resistivity for $\mathrm{Nd}_{0.75} \mathrm{Na}_{0.25} \mathrm{Mn}_{1-y} \mathrm{Cr}_{y} \mathrm{O}_{3}(0 \leq y \leq 0.05)$ manganites. Inset is $d \ln \rho / d T^{-1}$ vs $T$ for $\mathrm{Nd}_{0.75} \mathrm{Na}_{0.25} \mathrm{Mn}_{1-y} \mathrm{Cr}_{y} \mathrm{O}_{3}$

Meanwhile, Figure 4 shows the effect of $\mathrm{Cr}$-doped on temperature dependence of electrical resistivity in $\mathrm{Nd}_{0.75} \mathrm{Na}_{0.25} \mathrm{Mn}_{1-y} \mathrm{Cr}_{y} \mathrm{O}_{3}$ manganites for $y=0-0.05$ samples. All the samples with $y=0$, 0.02 and 0.05 exhibits an insulating behaviour and did not show any transition as temperature decreases. However, analysis of $d \ln \rho / d T^{-1}$ vs. $T$ (inset Figure 4) curve displays a peak which indicates $\mathrm{CO}$ state for sample $y=0$ and 0.02 with a $\mathrm{CO}$ transition temperature $T_{C O}$ around $210 \mathrm{~K}$ and $160 \mathrm{~K}$ respectively while no peak was observed for $y=0.05$ sample. The decreasing of $\mathrm{CO}$ transition temperature indicated the $\mathrm{Cr}$-doped also affected the resistivity data in the region of $\mathrm{CO}$ state under zero magnetic field which may be related to the suppression of $\mathrm{CO}$ state. Apart from that, the increasing of $\mathrm{Cr}$ content affected the intensity values of the resistivity which can be suggested due to the increase of carrier concentration as result of weakening the $\mathrm{CO}$ state [12]. The presence of $\mathrm{CO}$ and localizing the charge carrier can be suggested due to JT effect that contributes to the electron-phonon interaction [28]. Insulating behaviour can be related with JT effect as $\mathrm{Mn}^{3+}$ is known as JT ion which is the $e_{\mathrm{g}}$ electrons are localized and easier to be trapped in $\mathrm{MnO}_{6}$ octahedral, hence causing the phonon easier to be scattered by distortion [17].

\subsection{Magnetic properties}

Temperature dependence of the AC susceptibility $\left(\chi^{\prime}\right)$ measurement for all samples of $\operatorname{Pr}_{0.75} \mathrm{Na}_{0.25} \mathrm{Mn}_{1-x} \mathrm{Cr}_{x} \mathrm{O}_{3}$ manganites was shown in Figure 5. The parent compound $(x=0)$ showed paramagnetic (PM) to antiferromagnetic (AFM) transition with Neel temperature, $T_{N} \sim 129 \mathrm{~K}$ in line with a previous suggestion for by [26]. Increasing of $\mathrm{Cr}$ content induced paramagnetic (PM) into ferromagnetic (FM)-like with Curie temperature, $T_{\mathrm{C}}$ increases from $132 \mathrm{~K}(x=0.02)$ to $141 \mathrm{~K}(x=0.04)$ indicated the suppression of $\mathrm{CO}$. The $T_{C}$ was determined from the temperature corresponding to the minimum value from $\mathrm{d} \chi^{\prime} / \mathrm{d} T$ versus $T$ plots as shown in Figure 5. Considering those electrical properties, this can be suggested that the samples exhibit a FM-like phase due to double-exchange interaction involving $\mathrm{Mn}^{3+}-\mathrm{O}-\mathrm{Mn}^{4+}$ and $\mathrm{Cr}^{3+}-\mathrm{O}-\mathrm{Mn}^{3+}[29]$.

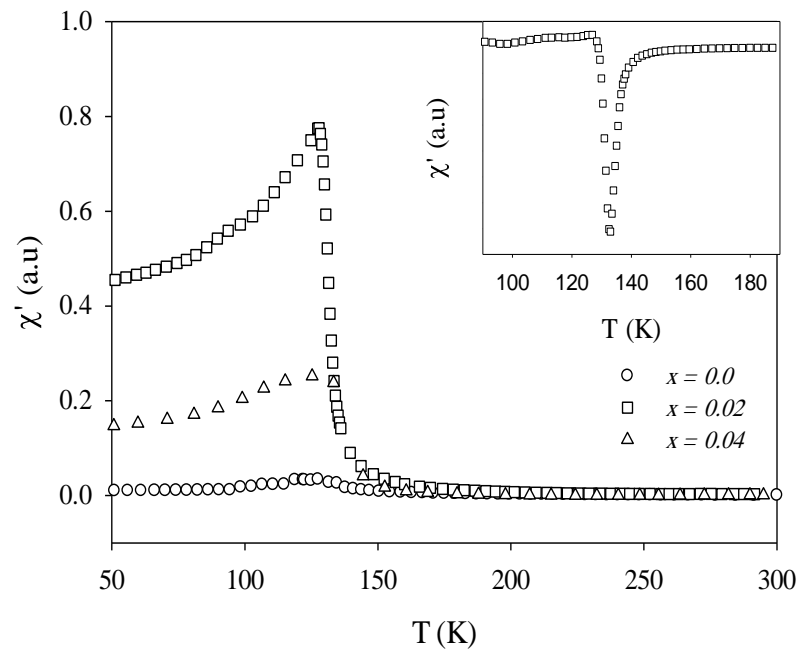

Fig. 5: Temperature dependence of $\mathrm{AC}$ susceptibility $\left(\chi^{\prime}\right)$ of $\mathrm{Pr}_{0.75} \mathrm{Na}_{0.25} \mathrm{Mn}_{1-x} \mathrm{Cr}_{x} \mathrm{O}_{3}(0 \leq x \leq 0.04)$. Inset is $d \chi^{\prime} / d T$ vs $T$ for $x=0.02$

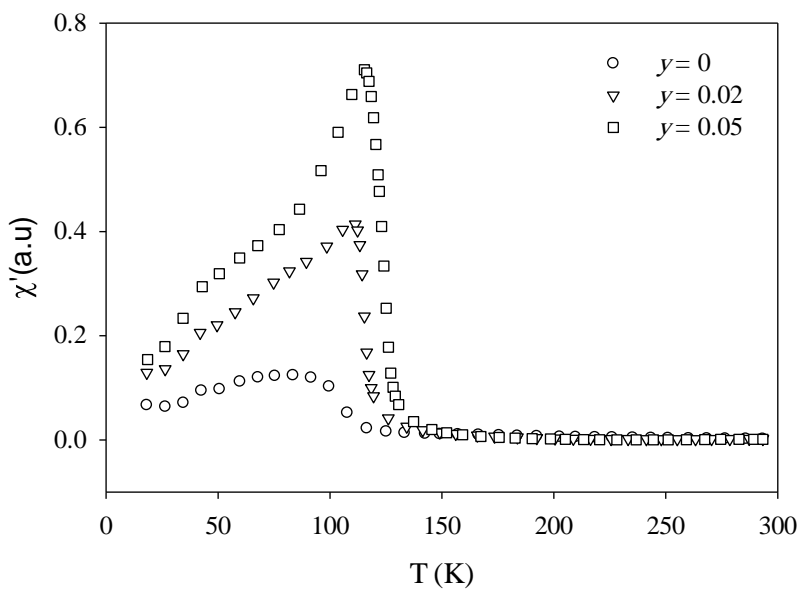

Fig. 6: Temperature dependence of AC susceptibility $\left(\chi^{\prime}\right)$ for $\mathrm{Nd}_{0.75} \mathrm{Na}_{0.25} \mathrm{Mn}_{1-y} \mathrm{Cr}_{y} \mathrm{O}_{3}(0 \leq y \leq 0.05)$ manganites.

The AC susceptibility $\left(\chi^{\prime}\right)$ versus temperature $(T)$ of $\mathrm{Nd}_{0.75} \mathrm{Na}_{0.25} \mathrm{Mn}_{1-y} \mathrm{Cr}_{y} \mathrm{O}_{3}$ compound is plotted in Figure 6. The temperature dependence of AC susceptibility reveals that all the samples shows paramagnetic (PM) to antiferromagnetic (AFM) transition with Neel transition temperature, $T_{N}$ increased from $115 \mathrm{~K}$ for $y=0.02$ to $125 \mathrm{~K}$ for $y=0.05$ indicate the suppression of CO state 
which is in line with the analysis of analysis of $d \ln \rho / d T^{-1} \mathrm{vs}$. T as shown in Figure 4.

\section{Conclusion}

In conclusion, the effects of $\mathrm{Cr}^{3+}$ doping on the structural, electrical transport properties and magnetic properties of $\operatorname{Pr}_{0.75} \mathrm{Na}_{0.25} \mathrm{Mn}_{1}$ ${ }_{x} \mathrm{Cr}_{x} \mathrm{O}_{3}(0 \leq x \leq 0.04)$ and $\mathrm{Nd}_{0.75} \mathrm{Na}_{0.25} \mathrm{Mn}_{1-y} \mathrm{Cr}_{y} \mathrm{O}_{3}(0 \leq y \leq 0.05)$ samples have been studied. By the XRD analysis for all samples, it is observed that $\mathrm{Cr}^{3+}$ could continuously replace $\mathrm{Mn}^{3+}$ based on the values of calculated unit cell volume, $V$ decrease continuously for both compound with $\mathrm{Cr}$ content suggestively due to the $\mathrm{Cr}^{3+}$ ion has a smaller ionic radius compare to $\mathrm{Mn}^{3+}$ ion. For $\mathrm{Pr}_{0.75} \mathrm{Na}_{0.25} \mathrm{Mn}_{1-x} \mathrm{Cr}_{x} \mathrm{O}_{3}$, the MI transition temperature, $T_{M I}$ increased with $\mathrm{Cr}$ doping from $120 \mathrm{~K}$ to $122 \mathrm{~K}$ for $x=0.02$ and $x=$ 0.04 respectively suggested due to the enhancement of DE mechanism as a result of weakening JT effect as well as suppress $\mathrm{CO}$ state. $\mathrm{Cr}^{3+}$ also suggestively involved in PM-FM transition resulting the increased of $T_{C}$ from $132 \mathrm{~K}(x=0.02)$ to $141 \mathrm{~K}(x=0.04)$ indicated the suppression of $\mathrm{CO}$. Meanwhile analysis of resistivity data of $d \ln \rho / d T^{-1}$ vs. $T$ in $\mathrm{Nd}_{0.75} \mathrm{Na}_{0.25} \mathrm{Mn}_{1-y} \mathrm{Cr}_{y} \mathrm{O}_{3}$ manganite showed a peak around $210 \mathrm{~K}$ and $160 \mathrm{~K}$ for $y=0$ and $0.02 \mathrm{sam}-$ ples respectively while no peak was observed for $y=0.05$ indicating the $\mathrm{Cr}$-doped affected the resistivity data in the region of $\mathrm{CO}$ state. Analysis of susceptibility from $\mathrm{Nd} 0.75 \mathrm{Na} 0.25 \mathrm{Mn}_{1-y} \mathrm{Cr}_{y} \mathrm{O}_{3}$ exhibit PM-AFM as Neel temperature $T_{N}$ increases from $115 \mathrm{~K}$ for $y$ $=0.02$ to $125 \mathrm{~K}$ for $y=0.05$ indicate the existing of $\mathrm{CO}$ state.

\section{Acknowledgement}

This research was supported by RAGS/1/2015/STD/UTHM/03/1 grant Vot R060 from the Malaysian Ministry of Higher Education. The author would like to thank the Material Physics Laboratory, Faculty of Applied Science and Technology, Pagoh Campus, Universiti Tun Hussein Onn Malaysia as well as Superconductor Laboratory, Faculty of Applied Sciences, Universiti Teknologi MARA Shah Alam for the facilities provided.

\section{References}

[1] Dagotto E, Hotta T \& Moreo A, "Colossal magnetoresistant materials: the key role of phase separation”, Physics review letter, Vol. 344, (2001), pp. 1-153.

[2] Goodenough JB, "Electronic structure of CMR manganites (invited)", Journal of Apply Physics, Vol. 81, No. 8, (1997), pp. 53305335 .

[3] Jin S, Tiefel TH, McCormack M, Fastnacht RA, Ramesh R \& Chen LH, "Thousandfold Change in Resistivity in Magnetoresistive LaCa-Mn-O Films", Science, Vol. 80, No. 264, (1994), pp. 413-415.

[4] Nagaev EL, "Colossal-magnetoresistance materials: Manganites and conventional ferromagnetic semiconductors", Physics Reports, Vol. 346, No. 6, (2001), pp. 387-531.

[5] Schultz L, Von Helmolt R, Wecker J, Holzapfel B and Samwer K, "Giant negative magnetoresistance in prevskite La2/3Ba1/3MnOx ferromagnetic films", Physics review letter, Vol. 71, No. 14, (1993), pp. 2331-2333.

[6] Tokura Y \& Tomioka Y, "Colossal magnetoresistive manganites", Journal of Magnetism and Magnetic Material, Vol. 200, No. 1-3, (1999), pp. 1-23.

[7] Ziese M, "Extrinsic magnetotransport phenomena in ferromagnetic oxides", Reports on Progress in Physics, Vol. 65, No. 2, (2002), pp. $143-249$.

[8] Li Y, Miao J, Sui Y, Wang X, Zhang W, Liu Y, Zhu R \& Su W, "Synthesis, structural and transport properties of Pr0.75Na0.25Mn1-xFexO3 $(0.0 \leq \mathrm{x} \leq 0.3)$ ", Journal of Alloys Compound, Vol. 441, No. 1-2, (2007), pp. 1-5.

[9] Zener C, "Interaction between the d-shells in the transition metal", Physics review, Vol. 82, No. 3, (1950), pp. 403-405.

[10] Hejtmánek J, Jirák Z, Šebek J, Strejc A \& Hervieu M, "Magnetic phase diagram of the charge ordered manganite Pr0.8Na0.2MnO3", Journal of Apply Physics, Vol. 89, No. 11, (2001), pp. 7413-7415.
[11] Satoh T, Kikuchi Y, Miyano K, Pollert E, Hejtmánek J \& Jirák Z, "Irreversible photoinduced insulator-metal transition in the $\mathrm{Na}$ doped manganite", Physical Review B, Vol. 65, No. 12, (2002), pp. 125103.

[12] Zhang X \& Li Z, "Influence of Cr-doping on the magnetic and electrical transport properties of $\mathrm{Nd} 0.75 \mathrm{Na} 0.25 \mathrm{MnO} 3$ ”, Journal of Rare Earths, Vol. 29, No. 3, (2011), pp. 230-234.

[13] Liu Y, Kong H \& Zhu C, "Coexistence of charge ordering and ferromagnetism in $\mathrm{Nd} 0.5 \mathrm{Ca} 0.5 \mathrm{Mn} 1-\mathrm{xCoxO} 3$ ( $\mathrm{x} \leq 0.1$ )", Journal of Alloys Compound, Vol. 439, No. 1-2, (2007), pp. 33.

[14] Hébert S, Maignan A, Hardy V, Martin C, Hervieu M, Raveau B, Mahendiran R \& Schiffer P, "Magnetization and resistivity steps in the phase separated $\mathrm{Pr} 0.5 \mathrm{Ca} 0.5 \mathrm{Mn} 1-\mathrm{xNixO} 3$ manganites", European Physical Journal B, Vol. 29, No. 3, (2002), pp. 419-424.

[15] Shamsuddin S, Ibrahim ABMA \& Yahya AK, "Effects of Cr substitution and oxygen reduction on elastic anomaly and ultrasonic velocity in charge-ordered $\mathrm{Nd} 0.5 \mathrm{Ca} 0.5 \mathrm{Mn} 1-\mathrm{xCrxO} 3-\delta$ ceramics", $\mathrm{Ce}$ ramics International, Vol. 39, (2013), pp. 185-188.

[16] Cao S, Li W, Zhang J, Kang B, Gao T \& Jing C, "Cr-dopinginduced phase separation and $\mathrm{MR}$ effect in the manganite Pr0.5Ca0.5Mn1-xCrxO3system", Journal of Apply Physics, Vol. 102, No. 5, (2007), pp. 0-6.

[17] Gao HP, Wu BM \& Li B, "Effect of Cr-doping on thermal transport property in perovskite R0.7A0.3Mn1-xCrxO3", Physical B: Condensed Matter, Vol. 389, No. 2, (2007), pp. 252-257.

[18] Sun $\mathrm{Y}$, Xu X \& Zhang $\mathrm{Y}$, "Effects of $\mathrm{Cr}$ doping in La0.67Ca0.33MnO3: Magnetization, resistivity, and thermopower.", Physical Review B: Condensed Matter and Materials Physic, Vol. 63, No. 5, (2001), pp. 1-5.

[19] Kahn ML, Hlil EK, Ellouze M, Elhalouani F, Sbissi K \& Collie V, "Fe doping effects on the structural, magnetic , and magnetocaloric", Journal of Nanostructure Chemistry, Vol. 3, (2015).

[20] Bettaibi A, M'nassri R, Selmi A, Rahmouni H, Chniba-Boudjada N \& Cheikhrouhou A, "Effect of chromium concentration on the structural, magnetic and electrical properties of praseodymiumcalcium manganite", Journal Alloys Compounds, Vol. 650, (2015), pp. $268-276$.

[21] Kumar N, Kishan H, Rao A \& Awana VPS, "Structural, electrical, magnetic, and thermal studies of Cr-doped $\mathrm{La} 0.7 \mathrm{Ca} 0.3 \mathrm{Mn} 1-\mathrm{xCrxO} 3(0 \leq \mathrm{x} \leq 1)$ manganites", Journal of Apply Physics, Vol. 107, No. 8, (2010), pp. 83905.

[22] Oumezzine M, Peña O, Kallel S, Kallel N, Guizouarn T, Gouttefangeas F \& Oumezzine M, "Electrical and magnetic properties of $\mathrm{La} 0.67 \mathrm{Ba} 0.33 \mathrm{Mn} 1-\mathrm{x}(\mathrm{Me}) \mathrm{xO} 3$ perovskite manganites: Case of manganese substituted by trivalent $(\mathrm{Me}=\mathrm{Cr})$ and tetravalent $(\mathrm{Me}=\mathrm{Ti})$ elements", Applied Physics A: Materials Science \& Processing, Vol .114, No. 13, (2014), pp. 819-828.

[23] Shamsuddin S, Ibrahim ABMA \& Yahya AK, "Effect of Er substitution on ultrasonic anomaly in Dy0.5-xErxBa0.5CoO3 cobaltates", Ultrasonics, Vol. 53, No.6, (2013), pp. 1084-1088.

[24] Shaikh MW, Mansuri I, Dar MA \& Varshney D, "Structural and transport properties manganites", Materials Science in Semiconductor Processing, Vol.35, (2015), pp. 10-21.

[25] Modi A \& Gaur NK," Structural, electrical and magnetic phase evolution of $\mathrm{Cr}$ substituted GdMn1-xCrxO3 $(0 \leq \mathrm{x} \leq 0.2)$ manganites", Journal of Alloys Compoun, Vol. 644, (2015), pp. 575-581.

[26] Rozilah R, Ibrahim N, Mohamed Z, Yahya AK, Khan NA \& Khan $\mathrm{MN}$, "Inducement of ferromagnetic-metallic phase in intermediatedoped charge-ordered Pr0.75Na0.25MnO3 manganite by K+ substitution", Physica B: Condensed Matter, Vol. 521, No.6, (2017), pp. 281-294.

[27] Hejtm J, Mary M \& Jirak Z, "Structure and magnetism in the Pr1xNaxMnO3 perovskites", Journal of Magnetism and Magnetic Material, Vol. 250, (2002), pp. 275-287.

[28] Goff RJ \& Attfield JP, "Charge ordering in half-doped manganites", Physical Review B: Condensed Matter and Materials Physics, Vol. 70, No. 14, (2004), pp. 8-11.

[29] Xiao X, Yuan S, Yin S, Chen L, Ren G, Miao J \& Yu G, "Electrical transport and magnetic properties of $\mathrm{La} 0.67 \mathrm{Ca} 0.33 \mathrm{Mn} 1-\mathrm{xCrxO} 3$ and $\mathrm{La} 0.67+\mathrm{xCa} 0.33-\mathrm{xMn} 1-\mathrm{xCrxO} 3(0.04 \leq \mathrm{x} \leq 0.08)$ ", Journal of Wuhan University of Technology-Mater. Sci. Ed, Vol. 23, No.4, (2008), pp. 463-466. 